\title{
Three
}

\section{SOME SPURIOUS PROOFS FOR THE PURE EGO}

\author{
Rem B. Edwards
}

Robert S. Hartman joined the faculty of the Department of Philosophy at The University of Tennessee, Knoxville, as a distinguished Research Professor in January, 1968 with plans (which did not always work out) to spend half of each year at The University of Tennessee and the other half at The National University of Mexico, where he was also Research Professor. During the winter quarter and the following spring quarter of 1968, Hartman taught graduate courses in Value Theory, using his then newly published book, The Structure of Value, as the primary text. These courses had an immense effect on the lives and thoughts of many people, including Rem B. Edwards, who at the time was Hartman's junior colleague and an Associate Professor at The University of Tennessee.

Edwards audited these courses (and several of Hartman's later courses) and had many lively debates with Hartman over pertinent issues. In the spring quarter of 1968, they had an open forum debate, attended by Hartman's students and many other faculty and students at The University of Tennessee. At this debate, Edwards presented his paper titled "Some Spurious Proofs for the Pure Ego," here published for the first time. On this occasion, Hartman gave an oral response; but he did not write his response until 1971. The following chapter of this book, Hartman's "Formal Axiology and Its Critics," includes his response to this critique and to many others.

In the following critique, Edwards gave no direct quotes from Hartman's works, so relevant quotes will be given below in this introduction. Edwards addressed four of Hartman's arguments that appear to show that Hartman's doctrine of the timeless intrinsic self is equivalent to Kant's doctrine of the Real or Pure Ego that is not in space or time. For Kant, space and time are merely forms of appearances, not of realities; and, on some interpretations of Kant, underlying the seeming plurality of persons, there is only one real person, a single Pure Ego. Kant wrote that "Commerce between the soul and phenomenal matter is quite inconceivable, for it could only take place in space. But the soul is not an object of 
perception...Bodies as bodies cannot affect the soul and the converse, because bodies can have no relations with a thinking being. "I

Edwards objected to (1) Hartman's argument from unique timeless experiences, according to which we experience timelessness and spacelessness in our most profound experiences of intrinsic valuation. As expressed by Hartman:

There is a delightful tale of the Persian poet Firdusi where a man experiences a whole life while putting his head in a bucket of water and right away pulling it out. Extrinsic time here is a few seconds, intrinsic time the qualitative infinity of a life.

You also know the famous relativity of sitting two minutes on a hot stove, and on a park bench with your sweetheart. The richer intrinsic time is, the shorter appears the corresponding extrinsic time; the poorer intrinsic time (the time of experience) is, the longer appears the corresponding extrinsic time. ${ }^{2}$

The subjects of intrinsic valuation are non-empirical things, or rather, empirical things in their non-empirical aspects. They are, as such, neither in time nor in space. When a thing is regarded as unique, all there is is this thing. Since time and space are defined as succession and interrelationship of things, where there is only one thing there is no time and no space in this sense. The thing itself is the world. ${ }^{3}$

The inner self, we said, is not in space and time. Where then is it? Everywhere. In other words, in the inner core of our Self we are intrinsically one with every other Self. The cones of our Selfhood all meet at the vertex. There is one community, one core, of all mankind. This reality Jesus called The Kingdom of God that is within us, Kant called it the Kingdom of Ends, Royce and others called it by other names. In it, intrinsically, we are all one; and when we do a bad thing everybody has done it with us and through us."

Edwards also objected to (2) the argument from meta-awareness, according to which the self-awareness of the total temporality of the self cannot be in time. As expressed by Hartman:

I can reflect upon my reflection of myself, and upon my reflection of myself, and so on ad infinitum...The whole succession of my reflection 
upon myself, thus, is an infinite denumerable series with cardinality $\aleph_{0} .$. For both thinkers [Josiah Royce and Richard Dedekindf 5 whatever a thinker thought, the thinker himself was not a part of the set of thoughts he thought. Thus although all the reflections upon myself, and the reflections upon these reflections, and the reflections upon the latter, etc., differentiate myself infinitely, they never cover the totality of myself, since there always remains the Self which must do the thinking. ${ }^{6}$

Next, Edwards critiqued (3) the argument from Bertrand Russell's theory of types, which says that whatever involves all of a collection cannot be a member of that collection. Applied to time, this means, Hartman believed, that the self which refers to the totality of time cannot itself be in time. As he put it:

According to the fundamental axiom of the theory of types, whatever involves all of a collection must not be one of the collection; the thinker must not, logically, be part of the set of his possible thought objects, in particular, not of the set of his auto-reflections - the set of his reflection upon the reflection upon...the reflection of himself. That which thus refers to all of a collection is of a higher logical order than the collection. If the collection itself is of order $x_{0}$, the higher order is $\kappa_{1}{ }^{7}$

Finally, Edwards protested against (4) the argument from the infinite divisibility of time, according to which any part of a Self's infinite time is as rich in properties as the whole of its time. Hartman wrote:

What is the "I"? It is that which makes one person out of the infinite fractions of your life in time and space... How many moments do you have in time? Fifty-two years, we'll say. How many days? 52 times 365 , or 18,980 days. How many hours? 455,520. How many minutes? How many seconds? There is an infinity of subdivisions we can make. So you have an infinity of life moments, and all of them have to be pulled together. ${ }^{8}$

For a particularly clear illustration of the principle of transfinite cardinality, that the part equals the whole, see the parable [of Jesus] of the Laborers in the Vineyard. ${ }^{9}$ 
After telling the parable of the Laborers in the Vineyard, in which laborers who work all day, for several hours, and for only one hour, are all promised and paid the same wage (which irritates those who work longer), Hartman asked:

What on earth does it mean? It does look unfair. And from the point of view of finite arithmetic, it is unfair. No business in the world is conducted this way. But this is infinity business that Jesus is talking about - this is the Kingdom of Heaven. No space or time. If there is no time, what difference does it make how long a man has worked? Everybody is there in eternity. One eternity is as eternal as another eternity, and the so-called ten-minute eternity is as eternal as the socalled twelve hour eternity; there are neither minutes nor hours. There is no space either. If there is no space, then there is no separation, because what separates you and me is the space between us. If there is no separation, then there are no separate pockets. If there are no separate pockets, what you have everybody has. What you don't have, nobody has. So it makes no difference who gets what. The dollar that goes to anyone goes to everyone. At the bottom of our spiritual Selves we are one community. All of us are one. ${ }^{10}$

Whiteheadian process philosophers deny that any segment of time is divisible into an infinite number of real parts. It is potentially divisible into an infinite number of parts only in human thought or imagination, but real temporal occasions are finite atomic durations, shorter than which nothing can be real. At the level of human consciousness, these atomic durations are about a tenth of a second long; at the level of sub-atomic events, according to quantum physics, temporal occasions must endure minimally for as long as Planck time, $10^{-3}$ seconds, in order to exist at all. In lesser intervals, nothing can exist; so time is not divisible into an infinite number of real units.

I wish to explain as clearly as I can why I do not accept the doctrine of the non-spatio-temporal Self which Professor Hartman has been urging upon us, and in the process of doing so I hope to show that it is not through sheer obduracy or lack of perceptiveness that I reject the doctrine. I wish to state first a general reason for rejecting the doctrine and then to examine some of the arguments which Professor Hartman has used in class and in his 
published writings to support the doctrine.

As a general reason for rejecting the doctrine, I offer the consideration that a non-spatio-temporal Self could have no relevance to ethics or value theory if the usual Kantian strictures are placed upon it. According to the Kantian position (to which Professor Hartman has not yet explicitly committed himself in class), the categories of cause and effect apply only to the realm of phenomena, including the realm of the empirical self, and do not apply at all to the realm of noumena or things in themselves, including the Real Self. If this causal doctrine is held in conjunction with the doctrine of non-spatio-temporality, then the Real Self could have no relevance to morality or value theory in the sense that such a Real Self could never be acted upon, could never be an effect; and it could never act, could never be a cause. No matter what the word "value" may ultimately turn out to mean, I do not think that we human beings are able to value anything unless that thing can affect us in some way. Also, it is only the kind of self which can function as a cause that can have moral duties. A cause-less self could never do anything, and if we accept the "cannot implies ought not (not obligated)" principle, then it could never have any moral duties to do anything. In what then could moral duty consist? Finally, if we define moral responsibility as being the originative cause of our actions, then a non-causal self could never be responsible for anything.

Now I wish to examine briefly some of the arguments used by Professor Hartman to prove the existence of a non-spatio-temporal-self, which will be called henceforth the "Pure Ego."

\section{The Argument from Unique Timeless Experiences}

According to this line of argument, we know that there is a Pure Ego because certain unique experiences occur in which we are not aware of spatio-temporality. As instances of this type of experience, Professor Hartman cited the cases of being in intense pain, like sitting on top of a hot stove, and of being reduced to silence, of being at a loss for words, and the experience of being in love. There is an ambiguity in the concept of "atemporality" which makes it initially plausible that in these experiences of timelessness we are transported into the realm of the Pure Ego. "Atemporal" may mean on the one hand "not being aware of time," and on the other hand it may mean "not being a datable event in time." Professor Hartman seems to move from the one to the other as if they were identical, but this is not the case. Many times I have had the experience of concentrating so completely on the book I was reading that I was unaware 
of being in my office, but it does not follow that I was not in my office simply because I was unaware of being there. Similarly, it does not follow that my experience of excruciating pain, or of being at a loss for words, is not a datable event in time simply because I am not aware of its being a datable event in time. Such magic moments do doubtless occur, but they are moments all the same.

When asked if it makes sense to ask "When do these unique experiences occur?" Professor Hartman answered affirmatively. It would appear that an affirmative answer to this question concedes that these experiences are events in time. I doubt that we ever have an experience of anything which cannot, upon later reflection, be recognized to be earlier than some experience and later that some other experience in the time series, even though the experience in question is one in which we are not aware of or attending to temporality. It is with the intent of avoiding this conclusion that Professor Hartman offers the next argument, which is not so much as argument as it is a postulate.

\section{The Argument from Meta-awareness}

It is contended that if our awareness of timelessness is an event in time, then this is only the awareness of the empirical self, not the awareness of the Pure Ego, which can be so dated. In order to arrive at the Pure Ego we must postulate an Awareness of awareness, a meta-awareness; and it is this meta-awareness which cannot be dated. Presumably, it is only when we arrive at this meta-awareness that it no longer makes sense to ask and answer: "When did it happen?"

About this argument, several remarks are in order. First of all, we must be clear that none of the appeals to unique experience discussed in Argument (1) provide any evidence for the existence of this meta-awareness as long as we are willing to date them as events in time. Has anyone ever had an experience of excruciating pain or a magic moment of love for which it was absolutely impossible for her or him to give at least a rough answer as to when it happened (for example, after I was born, or after I reached the age of puberty, and before I came to class today)? I doubt very seriously that anyone (including Professor Hartman) could give an honest affirmative answer to this question!

Second, it is precisely at the point where we have to postulate this nondatable type of awareness that philosophers from David Hume through Alfred North Whitehead and Charles Hartshorne have maintained that our theories lose contact with experience altogether. If this is the case (and I 
believe that it is), then no appeal to unique timeless experiences, and no appeal to any empirical evidence whatsoever, could be employed to support the Pure Ego theory. The only kind of experience which could support the theory would have to be an absolutely undatable experience.

Third, if the meta-experience about which we are perplexed does not happen at a certain time, then what is left of the claims that we have it, or that it happens to us? Is not all this talk about timeless meta-experience simply about happenings which do not happen? Is not the theory thus trapped in a contradiction?

Fourth, it should not be inferred that the expression "awareness of awareness" is shown to be a totally senseless expression by the above arguments. In one sense, it is senseless, totally foreign to experience and to logic, to say that we have non-datable experiences of datable experiences. But it is true to experience to say that we have datable experiences of datable experiences. Today my "self of the moment" remembers the pains, and loves, and silences of the self of yesterday or yesteryear. Memory is experience of experience, awareness of awareness, a type of metaexperience; but a memory is an event within time, a datable experience of a datable experience. There is no need whatsoever to postulate the existence of a Pure Ego in order to make sense of such expressions as "I am now aware that sometimes I am not aware of myself." The distinction between present and past self is all that we need. This simply means that "The self of the present moment remembers that the past self was attending to or concentrating upon something else (such as a book, or a pretty girl), not upon itself." The past self is identified as my past self because it belongs to the same causal series of conscious experiences as that to which my experience of the present moment belongs, and because it is remembered to have many if not most (but not all) of the properties that my present self has. Whiteheadians subscribe to a theory of relative selfidentity through time.

\section{The Argument from the Theory of Types}

Just how much metaphysical mileage can we get out of the theory of types? Professor Hartman apparently believes that we can get a great deal! It can be used to prove that a non-spatio-temporal self is a logical (we are now out of the realm of empirical arguments) requirement of the spatio-temporal self.

The theory of types has been offered by certain philosophers as a way of avoiding the logical paradoxes or contradictions which arise when a property 
is predicated of itself, or when a sentence is permitted to refer to itself, for example, the paradox of the Cretan who said that "All Cretans are liars." The theory of types forbids the type of self-reference which breeds such paradoxes. A property cannot be a member of the class of things to which it is predicated; a sentence cannot be a member of the class of things to which it refers.

I am not well enough versed in logical theory to argue in detail that there is something wrong with the metaphysical application of a logical theory such as that expressed in the previous paragraph, though I suspect that such an argument could be constructed. I wish to urge only that the following difficulties seem to arise if we attempt to get the sort of metaphysical mileage out of the theory of types that Professor Hartman attempts to get.

First, if I must be un-spatial in order to talk about the whole of space, and un-temporal in order to talk about the whole of time, would not the same pattern of reasoning prove that I must be un-real in order to talk about the whole of reality? I am not at all sure that $I$ have much use at all for these "whole of $\mathrm{X}$ " expressions, but presumably Professor Hartman does. I am simply saying that this seems to create a difficulty for him since the same pattern of argument which proves the non-spatio-temporality of the Pure Ego also proves its unreality!

Secondly, the line of argument which Professor Hartman has initiated seems also to generate an infinite regress of Pure Ego's (if it is admitted that the Pure Ego can talk or think about, know about, or have beliefs about itself). If a Pure Ego is required before I can talk about my empirical self, then what is required before I can talk about my Pure Ego? The obvious answer is that a Meta-Pure-Ego is needed! And then A Meta-Meta, and a Meta-Meta-Meta, and so on to infinity!

Finally, even if we admit that the theory of types does have metaphysical applications, an alternative account of self-knowledge can be provided which does not require a Pure Ego. Professor Charles Hartshorne, for example, contends that the self of the present moment, in the strictest intelligible sense of "present moment," can never literally know or talk about itself, since all introspective experience is actually retrospective experience on immediately past states of the present self, and since the self which begins the thought "my present self" is already in the past by the time that this thought is completed." Self-reference can thus be avoided without introducing a "Pure Ego." 


\section{The Argument from the Infinite Divisibility of Time}

The relevance of this one is awfully difficult to see, but Professor Hartman apparently wants to contend that the Whiteheadian theory of selfhood is mistaken because time is infinitely divisible. Some more elaborate reconstruction of the argument is doubtless required, since the conclusion here does not follow from the stated premise in any obvious way. And there is always the danger, in re-constructing an argument which was only incompletely stated, that it will be misconstructed. But allow me to make an attempt.

The argument seems to be that the Whiteheadian view that the self (in the broad sense of the series of causally continuous experiences which have temporarily terminated in the present moment of consciousness) has a beginning (somewhere close to birth) and an end (at death) is mistaken, since if the self endures for a short time, (as Whitehead admits), it therefore endures forever (because even a short period of time is infinite, is infinitely divisible). To put the matter another way, if the self endures for five minutes, it endures for eternity since five minutes has just as many parts as eternity, namely an infinite number. Thus, the self is eternal.

I am no expert in trans-finite mathematics, but I sense that there is something wrong with this argument somewhere. I can illustrate the difficulty by producing a parallel argument: If we have had five minutes of Professor Hartman's course in Value Theory, we have had it all, since there are as many parts in five minutes of the course as there are in thirty-five hours of it! Shall we adjourn?! 


\section{ENDNOTES}

1. Quoted by Harald Höffding, A History of Modern Philosophy, Vol. II, (New York: Dover Publications, 1955), p. 572, n. 15.

2. Robert S. Hartman, "Formal Axiology and Its Critics," this volume, p. 64.

3. Robert S. Hartman, "The Logic of Value," The Review of Metaphysics, 14:3 (March 1961), p. 422.

4. Robert S. Hartman, "The Value Structure of Personality," unpublished manuscript, p. 24.

5. [Hartman's reference here is to:] Josiah Royce, The World and the Individual, Vol. I, (New York: Macmillan, 1923), pp. 501 ff; and Richard Hocking, "The Influence of Mathematics on Royce's Metaphysics," Journal of Philosophy, 53 (2 February 1956).

6. Robert S. Hartman, "Four Axiological Proofs of the Infinite Value of Man," Kant-Studien, 55:4 (1954), p. 433.

7. Ibid., pp. 433-434.

8. Robert S. Hartman, Freedom to Live: The Robert Hartman Story, (Amsterdam - Atlanta: Editions Rodopi, 1994), pp. 75-76.

9. Robert S. Hartman, The Structure of Value: Foundations of Scientific Axiology, (Carbondale, Ill.: Southern Illinois University Press, 1969), p. 353, n. 33.

10. Hartman, Freedom to Live, p. 138.

11. Charles Hartshorne, Creative Synthesis and Philosophic Method, (La Salle, Ill.: The Open Court Publishing Co., 1970), p. 109. 